\title{
A 7-Layered E-Government Framework Consolidating Technical, Social and Managerial Aspects
}

\author{
Mohammed Hitham M.H, Dr. Hatem Elkadi H.K, Dr. Sherine Ghoneim S.G \\ Faculty of Computer and Information System \\ Cairo University \\ Cairo, Egypt
}

\begin{abstract}
E-Government has been hype for the last 2 decades and still several implementations do not reach the intended success. Different definitions and consequently different models of operations and assessment were developed. This required the formulation of various frameworks describing the different perceptions and understandings of e-Government. The different frameworks proposed tend to agree on a set of elements, but each framework seems to have one or few different elements, depending on the perception of the framework founder. Also, entire categories (or dimensions) of elements seem to be left out. Through a literature review and field survey, the authors identified challenges of an e-Government initiative, categorized in five dimensions: technical, adoption, organizational, strategy and cultural. Not all categories were covered in any of the existing government frameworks. This would prove to be awkward in the formulation of new government initiatives or in the assessment of existing ones and evolution plan. In an effort to represent the majority of the factors and elements involved in most e-Government initiatives, the authors present a proposed seven-layer-framework for e-government. The layers included are: 1) end user access layer, 2) e-government layer, 3) organization layer, 4) national infrastructure layer, 5) strategic layer, 6) social cultural layer, and 7) national execution layer. The proposed model is compared with existing models and demonstrates that it covers all the aforementioned dimensions.
\end{abstract}

Keywords-E-government; framework; e-government; challenges; decision support system (DSS)

\section{INTRODUCTION}

An e-government initiative is rather a complex endeavor, way beyond the technological complexity commonly presented by ICT professionals and vendors. Social, legislative and managerial aspects are major dimensions that are usually left out during the formulation of the E-Government implementation plans, and in the majority of the proposed frameworks. An integrative framework is required to provide a bird's eye overview of the diversity of factors and dimensions involved. In this quest, the different dimensions and factors pertaining to e-government initiatives were first identified; existing frameworks reviewed and then the proposed framework formulated. The rest of this paper is organized as follows: section two presents a survey of related work; identifying and categorizing the issues and challenges facing egovernment, and the coverage provided by each work. Section 3 discusses the e-government existing frameworks and the common features or layers covered in each, the Challenges addressed by each and finally the unaddressed ones. Section 4 presents the proposed e-government framework, discussing the significance of each element and the challenges it addresses. Section 5 presents a comparison between the proposed egovernment framework and the other frameworks, identifying the layers reported in previous frameworks, as compared to the proposed one. Finally, Section 6 summarizes the paper findings and presents planned objectives and possible extensions based on this work.

\section{Challenge FACING E-GOVERNMENT IMPLEMENTATION}

Through a review of the research literature concerned with the challenges facing e-government, we could categorize these challenges into five categories as shown in Table 1:

Technical [1]-[19], adoption [1]-[5], [7], [9], [11]-[20], organizational [1], [3]-[6], [8], [10]-[12], [14]-[17], [19]-[21], strategy [1], [3]-[5], [11]-[15], [19], [20] and cultural [1]-[6], [11]-[18], [22]. Many researchers have categorized challenges that faced e-government projects implementations, as summarized in Table 2.

\section{EXISTING FRAMEWORKS}

In our effort to identify the different e-government framework elements, the frameworks proposed by several authors are reviewed [14], [18], [23]-[27]. These frameworks are analyzed from two perspectives: Existing Layers (architecture) and the Categories of Challenges covered.

\section{A. Framework Layers}

The majority of existing frameworks covered included mainly the following main layers:

\section{1) Infrastructure layer}

According to (RoslindKaur, 2006) [23], the infrastructure includes network, backup and redundancy, and storage and according to (Mundy, D. and B. Musa, 2010) [18], the egovernment framework includes infrastructure such as network, IT education, and IT administration. According to (Zakareya Ebrahim, 2005) [24] and (Sharma, 2003) [25]and the infrastructure includes servers, LAN, internet, and extranet.

The ICT infrastructure layer is Omni-existent in different frameworks: (Hatem Ben Sta, 2014) [14]. 
TABLE I. CATEGORIZED ISSUES AND CHALLENGES FACING E-GOVERNMENT

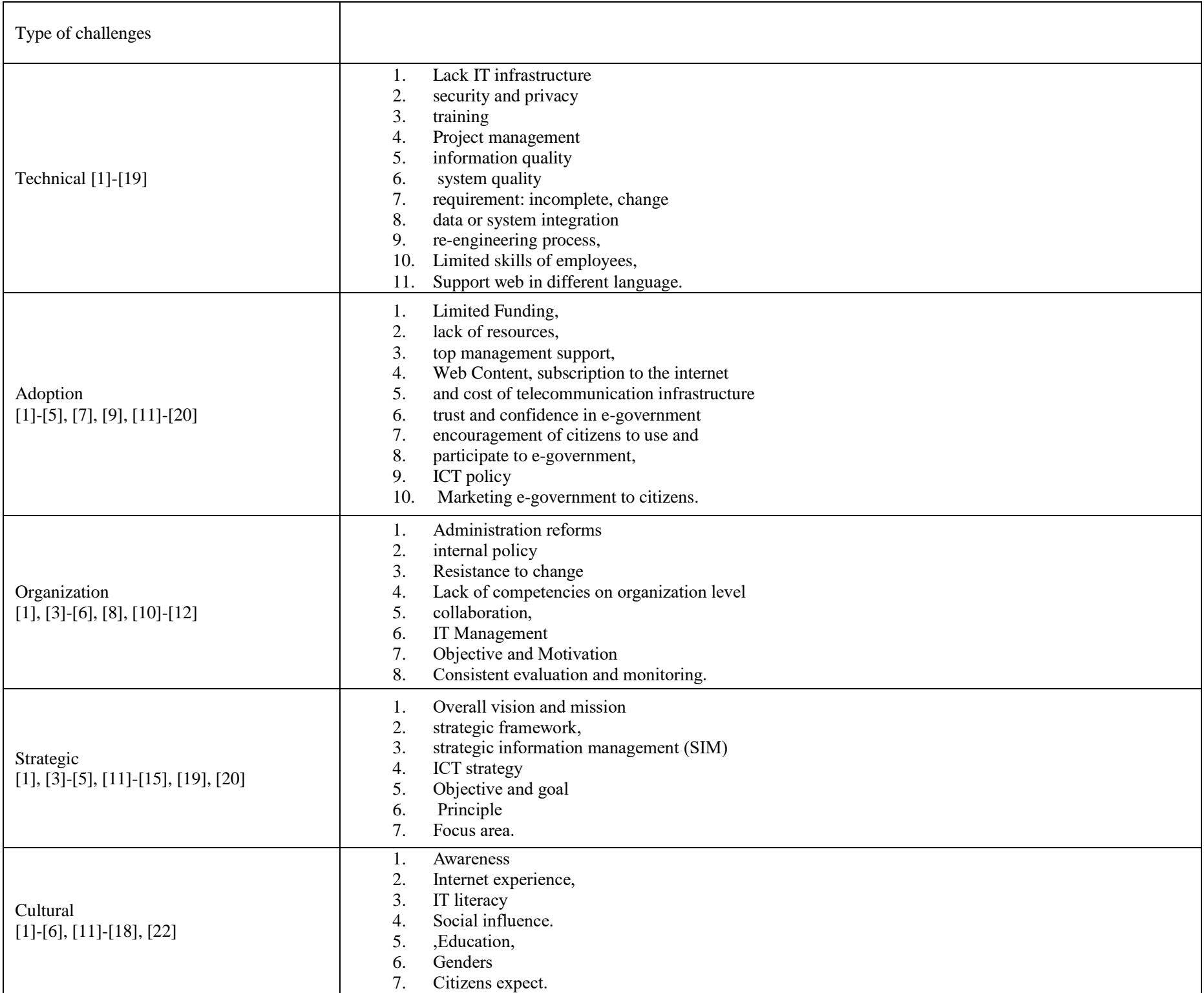

TABLE II. E-GOVERNMENT CHALLENGES CATEGORIES ADDRESSED BY RESEARCH

\begin{tabular}{|c|c|c|c|c|c|}
\hline \multirow[b]{2}{*}{ Researchers } & \multicolumn{5}{|c|}{ Challenges } \\
\hline & 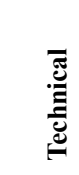 & 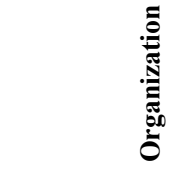 & 㐏 & 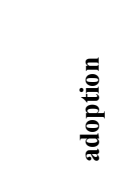 & $\frac{0}{0}$ \\
\hline Al-Khouri [20] & $\sqrt{ }$ & $\sqrt{ }$ & & $\sqrt{ }$ & $\sqrt{ }$ \\
\hline Alshehri, M [1] & $\sqrt{ }$ & $\sqrt{ }$ & $\sqrt{ }$ & $\sqrt{ }$ & $\sqrt{ }$ \\
\hline Al-Shafi, S. and V. Weerakkody [2] & $\sqrt{ }$ & & $\sqrt{ }$ & $\sqrt{ }$ & \\
\hline $\begin{array}{l}\text { AL-Naimat, A.M., M.S. Abdullah, and } \\
\text { M.K [3] }\end{array}$ & $\sqrt{ }$ & $\sqrt{ }$ & $\sqrt{ }$ & $\sqrt{ }$ & $\sqrt{ }$ \\
\hline Elkadi, H. & $\sqrt{ }$ & $\sqrt{ }$ & $\sqrt{ }$ & $\sqrt{ }$ & $\sqrt{ }$ \\
\hline
\end{tabular}




\begin{tabular}{|c|c|c|c|c|c|}
\hline $\begin{array}{l}\text { Abdelmoniem, E.M., S.A. Mazen, and } \\
\text { E.E. Hassanein [4], [5] }\end{array}$ & & & & & \\
\hline $\begin{array}{l}\text { Al-Hagery, M.A.H. } \\
\text { Alsohybe, N.T. } \\
\text { Al-Wazir, A.A. and Z. Zheng. } \\
\text { Al-Wazir, A.A. and Z. Zhen. [6], [7]-[10] }\end{array}$ & $\sqrt{ }$ & $\sqrt{ }$ & $\sqrt{ }$ & $\sqrt{ }$ & \\
\hline Halligan, J. and T. [11] & $\sqrt{ }$ & $\sqrt{ }$ & $\sqrt{ }$ & $\sqrt{ }$ & $\sqrt{ }$ \\
\hline Ramli, R.M.[12] & $\sqrt{ }$ & $\sqrt{ }$ & $\sqrt{ }$ & $\sqrt{ }$ & $\sqrt{ }$ \\
\hline Mutula, S.M. and J. Mostert [13] & $\sqrt{ }$ & & $\sqrt{ }$ & $\sqrt{ }$ & $\sqrt{ }$ \\
\hline Rijadi, D.A. and E. Satriya [14] & $\sqrt{ }$ & $\sqrt{ }$ & $\sqrt{ }$ & $\sqrt{ }$ & $\sqrt{ }$ \\
\hline Nkwe, N.[15] & $\sqrt{ }$ & $\sqrt{ }$ & $\sqrt{ }$ & $\sqrt{ }$ & $\sqrt{ }$ \\
\hline Kumar, R. and M.L. Monga, A [16], [17] & $\sqrt{ }$ & $\sqrt{ }$ & $\sqrt{ }$ & $\sqrt{ }$ & \\
\hline Mundy, D. and B. Musa [18] & $\sqrt{ }$ & & $\sqrt{ }$ & $\sqrt{ }$ & \\
\hline Chowdhury, H., M. Habib [19] & $\sqrt{ }$ & & $\sqrt{ }$ & $\sqrt{ }$ & $\sqrt{ }$ \\
\hline Ebrahim, Z. and Z [24] & $\sqrt{ }$ & $\sqrt{ }$ & & Financial & \\
\hline Hwang [28] & $\sqrt{ }$ & $\sqrt{ }$ & & & Legal \\
\hline
\end{tabular}

TABLE III. EXISTING Frameworks COVERAGE of Challenge CATEGORIES

\begin{tabular}{|c|c|c|c|c|c|}
\hline Frameworks/challenges & Technical & Organizational & Cultural & Adoption & Strategy \\
\hline $\begin{array}{l}\text { RoslindKaur, } 2006 \\
\text { "Malaysia" }\end{array}$ & $\begin{array}{l}\text { Cover only: } \\
\text {-IT infrastructure. } \\
\text { - Security and privacy. } \\
\text { - Data and system integration. }\end{array}$ & $\begin{array}{l}\text { Cover only: } \\
\text {-Collaboration. }\end{array}$ & - & $\begin{array}{l}\text { Cover only: } \\
\text {-Resources (access devices, } \\
\text { hardware/software) }\end{array}$ & \\
\hline $\begin{array}{l}\text { Mundy, D. and B. Musa, } \\
2010 \text { "Nigeria" }\end{array}$ & $\begin{array}{l}\text { Cover only: } \\
\text {-Network infrastructure } \\
\text {-IT management. }\end{array}$ & & - & $\begin{array}{l}\text { Cover only: } \\
\text {-Resources (access devices, } \\
\text { hardware/software) }\end{array}$ & \\
\hline Sharma, 2003 & $\begin{array}{l}\text { Cover only: } \\
\text {-IT infrastructure such as LAN, } \\
\text { servers. } \\
\text {-Data and system integration } \\
\text {-Data Management }\end{array}$ & & - & $\begin{array}{l}\text { Cover only: } \\
\text {-Resources (access devices, } \\
\text { hardware/software) }\end{array}$ & \\
\hline $\begin{array}{l}\text { Hatem Ben Sta, } 2014 \\
\text { "Tunisia" }\end{array}$ & $\begin{array}{l}\text { Cover only: } \\
\text {-IT infrastructure }\end{array}$ & $\begin{array}{l}\text { Cover only: } \\
\text {-Collaboration. }\end{array}$ & - & $\begin{array}{l}\text { Cover only: } \\
\text {-Resources (access devices, } \\
\text { hardware/software) } \\
\text {-Funding }\end{array}$ & \\
\hline $\begin{array}{l}\text { Harijadi, D.A. and E. } \\
\text { Satriya, } 2000 \text { "Indonesia" }\end{array}$ & $\begin{array}{l}\text { Cover only: } \\
\text {-IT infrastructure }\end{array}$ & $\begin{array}{l}\text { Cover only: } \\
\text {-Administrator reforms. }\end{array}$ & - & & \\
\hline $\begin{array}{l}\text { Kütt, A.andJ. Priisalu, } 2014 \\
\text { "Estonia" }\end{array}$ & $\begin{array}{l}\text { Cover only: } \\
\text {-IT infrastructure } \\
\text {-Data and system integration }\end{array}$ & & - & $\begin{array}{l}\text { Cover only: } \\
\text {-Resources (access devices) }\end{array}$ & \\
\hline $\begin{array}{l}\text { Rashty, B.C.a.D, } 2002 \\
\text { "Finance General } \\
\text { AccountantOffice-israel" }\end{array}$ & $\begin{array}{l}\text { Cover only: } \\
\text {-IT infrastructure. } \\
\text { - Security and privacy. }\end{array}$ & $\begin{array}{l}\text { Cover only: } \\
\text {-Collaboration. }\end{array}$ & - & $\begin{array}{l}\text { Cover only: } \\
\text {-Resources (access devices). }\end{array}$ & \\
\hline
\end{tabular}


2) E-government layer

This layer focus on integration of different organization data and services into one stop called web portal. Egovernment framework includes e-government layer, according to (Harijadi, D.A. and E. Satriya, 2000), (RoslindKaur, 2006), (Sharma, 2003), and (Zakareya Ebrahim, 2005).

\section{3) Data layer}

This layer contains integration database from different organizations government that use to support decision making. According to (RoslindKaur, 2006), (Sharma, 2003), and (Zakareya Ebrahim, 2005), e-government framework includes data layer.

4) Application layer and information layer

This layer contains e-government application such as ERP, and knowledge share information between organizations.

According to Zakareya Ebrahim, 2005; RoslindKaur, 2006 and Hatem Ben Sta, 2014 e-government include application and information layer.

\section{B. Covered Challenges}

The review of existing e-government frameworks coverage of the challenges identified in Section 2, each framework focused on specific issues and dropped others. Table 3 summarizes the challenges covered by each of these frameworks. From the table, it can be realized that the IT infrastructure challenges are covered in all frameworks and that the adoption and organizational challenges are dealt with at different levels in most of the frameworks.

On the other hand, the strategy and cultural challenges were not covered in the reviewed frameworks. So, it has been stipulated that corresponding layers/components needs to be introduced into our proposed e-Government framework to deal with the shortcomings emanating from neglecting the related challenges widely revealed during actual implementations.

\section{PROPOSED FRAMEWORK}

In this section, the proposed framework for e-government is presented and discussed. The first layer represents access layer that includes government users and channels of access. By using these channels, the e-government's web portal integrates all data, information, and services from several departments that are protected by authentication layer which represents e-government layer. The e-government layer connects to organization layer that manipulates and integrates data, process and applications within the organization body to make information and services available to e-government portal and provide effective and efficient government services. In the bottom layer, the national infrastructure layer (New) was introduced to reach out to all government ministries. The National Infrastructure layer includes technical, legislative and regulatory aspects necessary for the proper function of eGovernment (e.g. Law of Access to Information, electronic payment and banking, eID and signature). All layers connect to the strategy layer (New) responsible for the formulation of the national strategy and blueprint of e-Government. All layers also connect to socio-cultural layer (New), to account for the social and cultural aspects and specificities of the users and staff, including awareness and readiness. A National Execution layer (New) is introduced to coordinate e-government projects implementations across organizations and ensure its abidance to the national strategy. A corresponding chief information officer function was introduced to the organization layer to ensure this coordination. In this framework the following additional layers have been introduced: national infrastructure layer, national strategy, socio-cultural layer, and national executive body. The organization layer was amended with additional roles/functions (business process, organization chief information officer and Decision Support) as shown in Fig. 1. Each layer of the proposed framework will be discussed in the following section.

\section{A. Access Layer}

This layer involves the channels that users can access the various government services. This layer has two components which are end user and communication channel that will be discussed as follows:

\section{1) End user}

This layer identifies the e-government user categories: citizens, government employees, businesses, other government department and another community member such civil society organizations.

\section{2) Communication channel}

Government user can access various services through multiple communication channels (e.g. website, Mobile phone). This layer helps identify the access standards and technologies to information and services for each government user group across different channels.

\section{B. E- Government Layer}

This layer is about integrating data from various organizations into a web-portal of government services; in to one-stop e-government port.

This layer has three components which are e-government interface (portal), authentication layer and a Service Oriented Architecture enterprise Government services bus (ESB) according to [23], [29].

\section{1) E-government interface (web portal)}

This component focuses on integrating the websites from different organizations in one website called e-government web portal. This component allows user to obtain information or services through a single window, improving access to services, reducing waiting time, saving cost and improving the quality of services (Ho, 2002; Gant and Gant, 2001; Sharma and Gupta, 2002).

2) Authentication layer "portal authentication layer"

Authentication is a process used for several methods to identify government users that can allow them to access system and information, once the users have authenticated [29]; they can be able to use applications that have privileges to use them. Additional multiple authentication layers may be added for extra protection in the government environment.

3) Services oriented architecture (SOA) government enterprise services bus (ESB) 
E-government requires collaboration between government organizations and non-government organizations through using various systems. These systems use different data format, language, storage type and technologies thus issues of heterogeneity and interoperability of systems, like Jordan [30], thus, an integrated platforms are needed to enhance sharing of information and services between government organizations and non-government organizations. So, SOA can be used meeting these challenges [31]. ESB is an enterprise application platform that helps governments to develop open architecture, standards-based on integration solution and implementation (SOA).

\section{Organization Layer}

The organization layer covers the organizational infrastructure, data and information, business processes, applications and information management that coordinates with the national e-government executive body. One of the most important purposes of this layer is to increase efficiency and effectiveness. The national e-government executive body, one of the most purposes of this layer is to increase efficiency and effectiveness. According to survey of e-government frameworks weren't covered many challenges such as evaluation and monitoring challenge (in organizational challenges) and project management challenge (in technical challenges), so we propose organization (ministry) layer to overcome of these challenges. The organization layer is required to relate to the national strategy, national infrastructure and social cultural layer. The government services can generally be distributed between different government organizations. Organizational adjustments are required for the adoption of ICT and inter-departmental coordination [32]. In addition to ICT adoption, two main types of challenges exist: regulatory and internal resistance to change. With the implementations of e-government projects changes to organizational culture, legislation, policies, human resource and organizational structure [32]-[36] have to be performed.

\section{1) Organization chief information officer}

According to [4], [5], [19] many countries are suffering from uncontrolled the execution of the e-government projects, so these layers are responsible to control the executions of egovernment project in each organization (ministry). According to (Seligman, 1999) OCIO provides leadership for organization overall information technology (IT), IT Architecture, change management, determine priority and strategy of implementation.

\section{2) Business process layer}

Business process layer aims at mapping existing and updating processes as well as managing them [37].

According to Taylor et al., 1911; Deming et al., 1982 and Juran et al., 1988, the first step in gaining control over the organizations is to know and understand the basic processes. According to our survey that has been conducted, we found that there are many organizations in some countries which are still based on paper works [1], [4]-[10]. Therefore, these governments need to transform process from papers to computerize.

\section{3) Application layer}

The application layer includes the legacy systems that need to be integrated into online services delivery, new online systems, back-office systems, messaging and directory services [38], [39] as well as Decision support system (DSS) that are required to be integrated with the web portal. According to the conducted survey, there are several problems in decision taking in many governments [40]-[42]. Accordingly, a DSS framework for e-government has been proposed as well. The DSS framework contains six components (processes), data collection, data mining and OLAP, information processing, government knowledge, inference engine and information visualization.

\section{4) Data layer and information layer}

The ministries and organizations have separated database. This creates an obstacle to data exchange and service integration. Standardization of data and information formats, metadata, and data dictionaries are the elements of this layer [43], [44].

This layer includes citizens and employees' data and profiles, government data and data warehouses.

\section{5) Infrastructure layer (local)}

This layer consists of local technical infrastructure, infrastructure policy and infrastructure management, such as storage backup, and accessibility.

\section{National E-government strategy layer}

According to Heeks (2006), e-government strategy is defined as plan and guide how to transfer the government to response to e-government challenges. It is required to achieve organizational objectives. According to Abdelbaset, 2009 [27] the e-government strategy contains 'vision, objective, principles, focus area, building block, prioritized initiatives and implementation plan'. The e-government strategy was not included in the reviewed frameworks. From [36], [45], [46] it could be determined that major elements needs to be included in any government strategy:

1) Increasing public ICT awareness.

2) Formulation of a clear vision for prioritized $e$ government implementation.

3) Assess the success and failure factors before engaging in the implementation of a national e-government project.

4) Identify the regulations and laws required for the secure exchange of information.

5) Develop e-government standards including data standards, technical standards, application standards, business process standards, and privacy and security standards. 


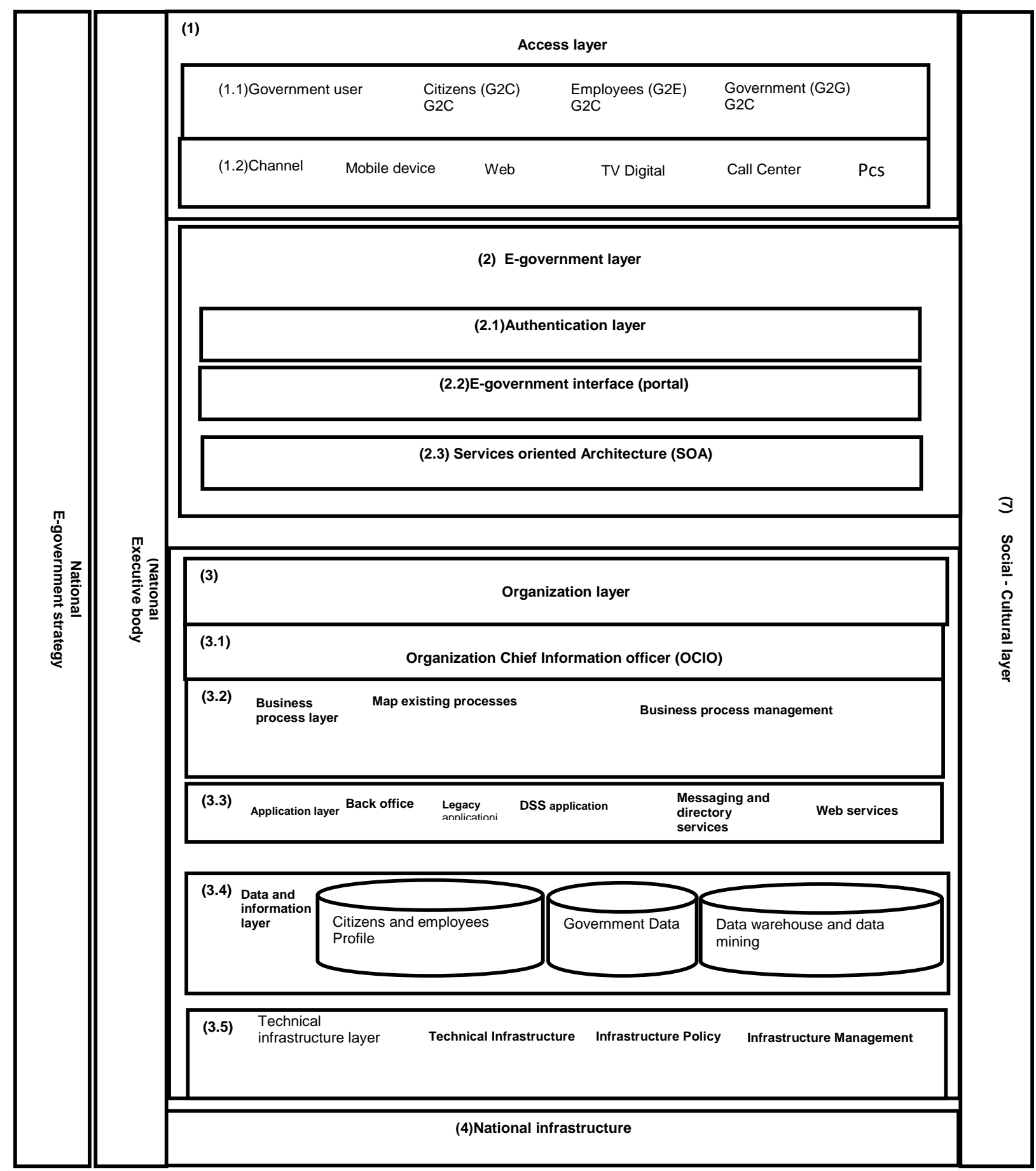

Fig. 1. Proposed e-government framework. 
TABLE IV. COMPARISON BETWEEN PREVIOUS AND THE PROPOSED E-GOVERNMENT FRAMEWORK

\begin{tabular}{|c|c|c|c|c|c|c|c|c|c|c|c|c|c|c|c|c|}
\hline \multirow[b]{2}{*}{ Comparison } & \multirow[b]{2}{*}{$\begin{array}{c}\text { Type of Framework: case study } \\
\text { or general (researcher) }\end{array}$} & \multicolumn{15}{|c|}{ Framework layers } \\
\hline & & 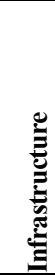 & 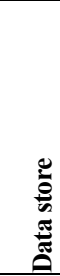 & 司 & ప⿱亠凶禸ઁ & 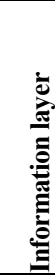 & لِّ & $\frac{\pi}{3}$ & 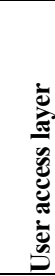 & 离 & 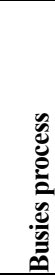 & 을 & 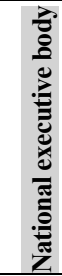 & 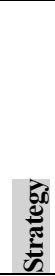 & 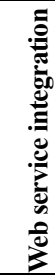 & 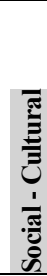 \\
\hline \multirow[t]{8}{*}{ Actual implementation FK } & Malaysia [23] & $\sqrt{ }$ & $\sqrt{ }$ & $\sqrt{ }$ & $\sqrt{ }$ & & & $\sqrt{ }$ & $\sqrt{ }$ & & & & & & & \\
\hline & Tunisia [47] & $\sqrt{ }$ & & $\sqrt{ }$ & & & $\sqrt{ }$ & & $\sqrt{ }$ & & & & & & & \\
\hline & Indonesia [14] & $\sqrt{ }$ & & & & & $\sqrt{ }$ & $\sqrt{ }$ & & & & & & & & \\
\hline & Nigeria [18] & & & & & & & & $\sqrt{ }$ & & & & & & & \\
\hline & Estonia [48] & $\sqrt{ }$ & $\sqrt{ }$ & $\sqrt{ }$ & & & & & & & & & & & & \\
\hline & Israel [49] & $\sqrt{ }$ & & $\sqrt{ }$ & & & & $\sqrt{ }$ & $\sqrt{ }$ & & & & & & & \\
\hline & New Zealand [50] & $\sqrt{ }$ & & $\sqrt{ }$ & $\sqrt{ }$ & $\sqrt{ }$ & & & $\sqrt{ }$ & & $\sqrt{ }$ & & & & & \\
\hline & Australia [51] & $\sqrt{ }$ & & & & & & $\sqrt{ }$ & $\sqrt{ }$ & & & & & & $\sqrt{ }$ & \\
\hline \multirow[t]{3}{*}{ Theoretical FK } & Zakareya[24] & $\sqrt{ }$ & & & $\sqrt{ }$ & $\sqrt{ }$ & & $\sqrt{ }$ & $\sqrt{ }$ & $\sqrt{ }$ & & & & & & \\
\hline & Sharma [25] & $\sqrt{ }$ & & & & & & $\sqrt{ }$ & $\sqrt{ }$ & & & & & & & \\
\hline & Y. N[27] & $\sqrt{ }$ & & & & & & & & & & & & & & \\
\hline Proposed Framework & & $\sqrt{ }$ & $\sqrt{ }$ & $\sqrt{ }$ & $\sqrt{ }$ & $\sqrt{ }$ & $\sqrt{ }$ & $\sqrt{ }$ & $\sqrt{ }$ & $\sqrt{ }$ & $\sqrt{ }$ & $\sqrt{ }$ & $\sqrt{ }$ & $\sqrt{ }$ & $\sqrt{ }$ & $\sqrt{ }$ \\
\hline
\end{tabular}

\section{E. National Executive Body (NEB)}

Top management support challenge (in adoption challenge) not covered in e-government frameworks that have been reviewed, so this layer is added to proposed framework. .NEB is the administrator of e-government project as the whole. It is linked to the president of council of Ministers to ensure access support. NEB is responsible for ensuring organization interoperability, data and information sharing, maintain information security and privacy controls across the ministries.

\section{F. Social Cultural Layer}

From Table 3, it can be noticed absence of cultural challenges from e-government frameworks, so this layer is added to our framework. This layer aims to evaluate readiness of society to use e-government such as determine percent of computer literacy and readiness local and national infrastructure to provide government services. This layer treats the identified lack of readiness and awareness in developing countries and cultural obstacles such as discrimination between male and female, IT literacy and education. This layer impacts on access layer and is influenced by organization layer, national infrastructure and National strategy.

\section{G. National infrastrcture layer}

National infrastructure includes the essential elements of communication infrastructure such as systems, processes and net-work. The purpose of this layer is to increase availability, and integration of services through the internet. It consists of the national network and national policy. National infrastructure is influenced by national strategy and impacts on organization layer and social cultural layer.

\section{COMPARISON TO OTHER FRAMEWORKS}

In this section, the proposed framework is compared with previous e-government frameworks as summarized in Table 4, the listed frameworks are categorized as theoretical (academic) and country-specific implementation frameworks. It can be clearly noted that the strategy, the CIO and the national executive body (management), as well as the Social-Cultural layers (dimensions) were not addressed by any of the reviewed frameworks, whereas the proposed model addresses them as well as all the other layers in other frameworks.

\section{CONCLUSION AND FUTURE WORK}

This paper is presented an identification of the different 
challenges facing e-government implementations. A review of existing e-government frameworks are presented, their structures and the challenges they handle. A set of challenges unhandled by exiting frameworks are identified and introduced corresponding layers to handle them.

There are some common layers between most egovernment frameworks such as application layer, web portal layer, user interface, and infrastructure layer. In this framework the following layers have been introduced: national infrastructure layer, national strategy, socio-cultural layer, and national executive body. The organization layer was amended with additional roles/functions (business process, organization chief information officer and decision support).

This framework has been divided into seven layers which are:

1) Access layer.

2) E-government layer.

3) Organization layer.

4) National E-government strategy layer.

5) National infrastructure.

6) National executive body.

7) Socio-Cultural layer.

Eventually, this framework has been evaluated by comparing it with previous frameworks: theoretical and implementation framework. It has been found; the proposed framework includes all layers in previous frameworks as well as has additional layer.

Similar to other frameworks, the current one does not either provide for an execution plan nor for an implementation structure to guarantee success.

Future work would cover the formulation of a high level implementation plan and organizational structure capable of implementing the foreseen plan.

Also, the authors foresee the application of the proposed model to existing e-government implementations, which may reveal the implicit existence of some of the proposed additional layers, while not explicitly represented in the reported frameworks.

\section{REFERENCES}

[1] Alshehri, M. and S. Drew, Challenges of e-government services adoption in Saudi Arabia from an e-ready citizen perspective. Education, 2010. 29(5.1).

[2] Al-Shafi, S. and V. Weerakkody, Factors affecting e-government adoption in the state of Qatar. 2010.

[3] AL-Naimat, A.M., M.S. Abdullah, and M.K. Ahmad. The Critical Success Factors for E-Government Implementation in Jordan. in Proceedings of the 4th International Conference on Computing and Informatics, University of Utara, Malaysia. 2013.

[4] Elkadi, H., Success and failure factors for e-government projects: A case from Egypt. Egyptian Informatics Journal, 2013. 14(2): p. 165-173.

[5] Abdelmoniem, E.M., S.A. Mazen, and E.E. Hassanein, Governance of Post-Construction Activities in IS Development Projects. International Journal of Computer Science Issues(IJCSI), 2012. 9(5).

[6] Ramli, R.M., Malaysian e-government: issues and challenges in public administration. International Proceedings of Economic Development and Research 2012. 22: p. 61-74.
[7] Al-Hagery, M.A.H., Basic Criteria for the Purpose of Applying EGovernment in the Republic of Yemen. International Journal of Research \& Reviews in Computer Science, 2010. 1(3).

[8] Alsohybe, N.T., The implementation of e-government in the Republic of Yemen: An empirical evaluation of the technical and organizational readiness. 2007.

[9] Al-Wazir, A.A. and Z. Zheng, Factors Influencing E-government Implementation in Least Developed Countries: A Case Study of Yemen. Developing Country Studies, 2014. 4(7): p. 20-29.

[10] Al-Wazir, A.A. and Z. Zheng, E-government development in Yemen: assessment and solutions. J Emerg Trends Comput Inf Sci, 2012. 3(4): p. 512-518.

[11] Halligan, J. and T. Moore, E-government in Australia: The challenges of moving to integrated services. 2004.

[12] Ramli, R.M., Malaysian e-government: issues and challenges in public administration. International Proceedings of Economic Development and Research, 2012. 48(2): p. 19-23.

[13] Mutula, S.M. and J. Mostert, Challenges and opportunities of egovernment in South Africa. The Electronic Library, 2010. 28(1): p. 3853.

[14] Harijadi, D.A. and E. Satriya. Indonesia's Road Map to e-Government: Opportunities and Challenges. in APEC high-level symposium on egovernment. 2000.

[15] Nkwe, N., E-government: challenges and opportunities in Botswana. International journal of humanities and social science, 2012. 2(17): p. 3948.

[16] Kumar, R. and M.L. Best, Impact and sustainability of e-government services in developing countries: Lessons learned from Tamil Nadu, India. The Information Society, 2006. 22(1): p. 1-12.

[17] Monga, A., E-government in India: Opportunities and challenges. JOAAG, 2008. 3(2): p. 52-61.

[18] Mundy, D. and B. Musa, Towards a framework for egovernment development in Nigeria. Electronic Journal of E-government, 2010. 8(2): p. $148-161$.

[19] Chowdhury, H., M. Habib, and I. Kushchu. Success and failure factors for e-Government projects implementation in developing countries: A study on the perception of government officials of bangladesh. in The Proceedings of Euro mGov. 2006.

[20] Al-Khouri, A.M., eGovernment strategies the case of the United Arab Emirates (UAE). European Journal of ePractice, 2012. 17: p. 126-150.

[21] Alraimi, K.M., Towards a Sustainable e-Government Infrastructure Initiative: The Case of Yemen. School of Engineering Korea Advanced institute of Science and Technology, 2009.

[22] Al-hashmi, A. and S. Suresha, Evaluating the Awareness of Egovernment in the Republic of Yemen. International Journal of Computer Applications, 2013. 67(16): p. 41-45.

[23] Kaur, R., Malaysian e-government implementation framework, 2006, University of Malaya.

[24] Ebrahim, Z. and Z. Irani, E-government adoption: architecture and barriers. Business process management journal, 2005. 11(5): p. 589-611.

[25] Sharma, S.K. and J.N. Gupta, Building blocks of an e-government: A framework. Journal of Electronic Commerce in Organizations (JECO), 2003. 1(4): p. 34-48.

[26] Sta, H.B., Malaysian e-government: issues and challenges in public administration 2014.

[27] Chen, Y., et al., E-government strategies in developed and developing countries: An implementation framework and case study. Journal of Global Information Management, 2006. 14(1): p. 23.

[28] Hwang, M.-S., et al., Challenges in e-government and security of information. Information \& Security, 2004. 15(1): p. 9-20.

[29] Yan, M. and F. Zhi-hua, Research on Web/Portal Authentication Technology [J]. Microelectronics \& Computer, 2004. 8: p. 021.

[30] Saleh, Z.I., R.A. Obeidat, and Y. Khamayseh, A Framework for an Egovernment Based on Service Oriented Architecture for Jordan. International Journal of Information Engineering and Electronic Business, 2013. 5(3): p. 1. 
[31] Keen, M., et al., Patterns: Implementing an SOA using an enterprise service bus. IBM Redbooks, 2004. 336.

[32] Nograšek, J., Change management as a critical success factor in egovernment implementation. Business Systems Research, 2011. 2(2): p. 13-24.

[33] Ojo, A., et al., Human Capacity Development for e- Government. UN University International Institute for Software Technology, Macau, UNUIIST Report, 2007(362).

[34] Kanungo, S. and V. Jain, Organizational culture and e-government performance: An empirical study. E-Government Services Design, Adoption, and Evaluation, 2012: p. 141.

[35] Almutairi, N., The Impact of Organizational Culture on the Adoption of E-Management" Evidence from Public Authority for Applied Education and Training (PAAET) in Kuwait". International Journal of Business and Management, 2014. 9(9): p. 57.

[36] Evans, D. and D.C. Yen, E-government: An analysis for implementation: Framework for understanding cultural and social impact. Government Information Quarterly, 2005. 22(3): p. 354-373.

[37] Röglinger, M., J. Pöppelbuß, and J. Becker, Maturity models in business process management. Business Process Management Journal, 2012. 18(2): p. 328-346.

[38] Markellou, P., A. Panayiotaki, and A. Tsakalidis. E-Government and Applications Levels. in Proceedings of IADIS Conference e-Society, Portugal. 2003. Citeseer.

[39] Cavanaugh, E., Web services: Benefits, challenges, and a unique, visual development solution. white paper, Feb, 2006. 10.

[40] Riad, A., et al. Effective and Secure DSS for E-Government. in WSEAS International Conference. Proceedings. Recent Advances in Computer Engineering Series. 2012. WSEAS.
[41] Rao, G.K. and S. Dey, Decision support for e-governance: a text mining approach. arXiv preprint arXiv:1108.6198, 2011.

[42] Van der Aalst, W.M., Using Process Mining to Bridge the Gap between BI and BPM. IEEE Computer, 2011. 44(12): p. 77-80.

[43] Alasem, A., An overview of e-government metadata standards and initiatives based on Dublin Core. Electronic Journal of e-Government, 2009. 7(1): p. 1-10.

[44] Weibel, S., et al., Dublin core metadata for resource discovery, 1998.

[45] West, D.M., E-government and the transformation of service delivery and citizen attitudes. Public administration review, 2004. 64(1): p. 15-27.

[46] Rabaiah, A. and E. Vandijct, A Strategic Framework of e-Government: Generic and best Practice". Leading Issues in e-Government Research, Academic Publishing International Ltd, 2011: p. 1-32.

[47] Bouchnak, Tunisia's e-Government Experience. 2013.

[48] Kütt, A. and J. Priisalu. Framework of e-government technical infrastructure. Case of Estonia. in Proceedings of the International Conference on e-Learning, e-Business, Enterprise Information Systems, and e-Government (EEE). 2014. The Steering Committee of The World Congress in Computer Science, Computer Engineering and Applied Computing (WorldComp).

[49] Rashty, B.C.a.D., The Five Layers Model of e-Government. Ministry of Finance General Accountant Office, 2002. 23(2): p. 207-235.

[50] Abdelkader, A., A cooperative intelligent decision support system for contingency management. Journal of Computer Science, 2006. 2(10): p. 758-764.

[51] Government, A., The Australian Government Business Process Interoperability Framework. 2007. 